\title{
POVOS INDÍGENAS E INTERCULTURALIDADE: O PLURALISMO JURÍDICO LATINO-AMERICANO
}

\author{
Luyse Vilaverde Abascal Munhós ${ }^{1}$ \\ Antônio Hilário Aguilera Urquiza ${ }^{2}$
}

\section{RESUMO}

A adoção da cultura jurídica que sedimentou a ordem normativa atual remonta à exportação do modelo de Estado Moderno da Europa para suas colônias. O objetivo é verificar a viabilidade da adoção do pluralismo jurídico para a edificação de uma sociedade de compartilhamento de saberes jurídicos com influências recíprocas. A metodologia de execução tem como alicerce o método dedutivo hipotético e parte de uma análise histórica e bibliográfica. A conclusão que se afere é a possibilidade de transformação do Estado monista em Estado plural, baseado no diálogo intercultural, na autonomia dos povos tradicionais e no pluralismo jurídico.

Palavras-chave: Monismo jurídico; Juridicidades alternativas; Colonialidade; Diálogo intercultural; Decolonialidade.

\section{INDIGENOUS PEOPLE AND INTERCULTURALITY: THE LATIN AMERICAN LEGAL PLURALISM}

\begin{abstract}
The adoption of the legal culture that underpinned the current normative order dates back to the export of the European Modern State model to its colonies. The objective is to verify the feasibility of adopting legal pluralism to build a society that contributes with legal knowledge with reciprocal influences. The execution methodology is based on the hypothetical deductive method and it initiates on a historical and bibliographical analysis. The conclusion that follows is the possibility of transform the monist and homogeneous state into a plural state, based on intercultural dialogue, the autonomy of traditional peoples and legal pluralism.
\end{abstract}

Key words: Legal monism; Alternative jurisdictions; Coloniality; Intercultural dialogue; Decoloniality.

\section{INTRODUÇÃO}

A diversidade cultural dos povos indígenas contesta a lógica do Estado moderno e da unicidade do elemento constitutivo que diz respeito ao povo, isso porque a forma clássica de Estado foi imaginada a partir do conceito de nação e sua unidade cultural homogênea, motivo

\footnotetext{
1 Mestranda em Direito pela Universidade Federal de Mato Grosso do Sul - UFMS. Email: munhosluyse@gmail.com

2 Doutor em Antropologia; Professor do Mestrado em Direitos Humanos/UFMS; Professor colaborador do Programa de Pós-Graduação em Antropologia (UFGD) e Programa de Educação (UCDB). Email: hilarioaguilera@gmail.com
} 
pelo qual o projeto de construção da identidade nacional perpassa a supressão da multietnicidade.

Apesar da Constituição brasileira de 1988 inovar no tratamento dos povos indígenas, ao estabelecer um viés multicultural e afastar o paradigma assimilacionista dos textos constitucionais anteriores, ainda sim consolida uma organização formal de Estado vinculada ao modelo clássico, estabelecendo uma nação brasileira culturalmente coesa e apontando os povo indígenas como exceções culturais e grupos contextualmente inexpressivos.

Após mais de 30 anos da promulgação da Constituição de 1988, as comunidades indígenas persistem em constante processo de luta, pois sofrem graves ameaças a sua sobrevivência física e cultural e são vítimas de sangrentos conflitos fundiários, eventos que se dão em decorrência da falta de efetivação dos comandos constitucionais pela prática constitucional assimilacionista dos três Poderes da República.

Experiências constitucionais latino-americanas, posteriores à promulgação da Constituição brasileira de 1988, demonstram que o multiculturalismo e o mero reconhecimento da diversidade étnica não é suficiente para a efetiva proteção de grupos culturalmente diferenciados, visto que são necessários novos modelos de convivência política entre diferentes nações em um mesmo território.

Por conseguinte, a proposta de reconhecimento da composição pluriétnica do Estado é apresentada pelo constitucionalismo pluralista latino-americano, que se propõe a refundar as bases dos Estados nacionais e consagrar ordenamentos jurídicos abertos às cosmovisões indígenas e suas juridicidades próprias.

Não é o caso, contudo, de apostar em uma normatividade transformadora da realidade concreta dos povos indígenas, esquecendo-se do legado de subserviência de países da periferia global ao sistema internacional reprodutor e explorador das assimetrias criadas pelo colonialismo. Por mais plurais que sejam os desenhos institucionais impulsionados pelos Estados Plurinacionais, há que se pontuar a atuação dos agentes políticos e econômicos, em nível global, e a posição debilitada do direito como garantidor da pluralidade em um contexto de domínio do sistema econômico internacional.

A necessidade da abordagem do tema reside no fato de que a conjuntura brasileira atual é hostil aos povos indígenas, considerados adversários do projeto desenvolvimentista esperado para o Brasil, pois vítimas da invasão das suas terras, e, muitas vezes, impelidos a 
viver em reservas diminutas e inadequadas para sua reprodução física e cultural, o que contribui para um quadro de verdadeira vulnerabilidade.

Ante esse cenário de histórica marginalização, aliado com a constante resistência indígena, é necessário averiguar as contribuições teóricas proporcionadas pelos fenômenos constitucionais da América Latina, que, de forma muito mais adequada, têm tratado a relação entre Estado e os povos indígenas.

Aliás, referida discussão tem sido substancialmente negligenciada pela doutrina constitucional brasileira, que de bom grado introduz conceitos e institutos de matriz euronorte-americanos, mas ignora a abordagem intercultural trazida pelo constitucionalismo instaurado em países que compartilham o mesmo legado do colonialismo, fato que se dá, muitas vezes, por visões estigmatizadas e meramente político-ideológicas.

Logo, essencial um estudo analítico aberto ao debate da nova teoria constitucional exibida pelo constitucionalismo pluralista latino-americano, que contraria o pensamento tradicional e sedimenta a coexistência das cosmovisões indígenas em um espaço de superação das relações coloniais.

O presente artigo destina-se a apontar a herança colonial das instituições jurídicas latino-americanas, de modo que o estabelecimento do conceito de Estado nação e a instrumentalização do monismo jurídico operaram como forma de suprimir a pluralidade presente na região, submetendo as diferentes perspectivas de mundo a um pensamento monolítico único e incontestável.

Para tanto, a metodologia empregada tem bases descritivas exploratórias, aliadas ao método hipotético-dedutivo de abordagem das contribuições latino-americanas no contexto brasileiro, possibilitadas pela análise de materiais bibliográficos, legais e documentais que instruem a hipótese de que o novo momento constitucional é capaz de desafiar as estruturas coloniais estruturalmente consolidadas pelo colonialismo.

Compreender a realidade dos povos indígenas na contemporaneidade demanda, ainda que de forma fragmentária, um apanhado histórico-jurídico da opressão colonial presente em séculos de subordinação e dominação, desde a exploração colonial do Império até a renovação da colonialidade do poder pelos Estados nacionais independentes.

Assim, apresenta-se uma contextualização do processo de construção do Estado monocultural brasileiro, pois calcado pela sistemática exclusão dos povos indígenas, seja dos processos decisórios seja pela perdurável estratificação social. 
Nesse exercício, fundamental se faz também tecer observações iniciais acerca da quebra de paradigma realizada pelos projetos constitucionais de países latino-americanos, em especial da Bolívia e do Equador, em um claro exercício do diálogo intercultural para abertura do ordenamento jurídico às cosmovisões indígenas e da construção de uma sociedade de compartilhamento de saberes com influências recíprocas, assumindo o pressuposto de que existem outras fontes legítimas de produção de direito diverso do estatal.

Contudo, imprescindível pontuar o impacto das limitações econômicas e jurídicas do próprio Estado sobre a viabilidade dos projetos constitucionais latino-americanos de caráter descolonial, tendo em vista que a ruptura com a dominação epistemológica, para produzir resultados práticos, sujeita-se à realidade política e econômica de um contexto regional e internacional marcado pela centralização do poder e pela continuidade de modelos econômicos extrativistas.

Por fim, a temática da abordagem intercultural, proposta pelo constitucionalismo latino-americano, é extremamente atual e requer espaço para debate, tendo em vista que se compromete com uma cultura jurídica descolonizada e leva em conta raízes históricas e práticas sociais dos povos originários do continente, ainda que as reformas jurídicas e políticas promovidas dependam de uma transformação no plano internacional, o que requer certa cautela associada à consciência quanto aos limites de qualquer configuração estatal.

\section{HERANÇA COLONIAL: ESTADO E MONISMO JURÍDICO}

O Estado Moderno como modelo de organização social institucional fundamenta-se na delimitação de um espaço territorial, na composição de uma base social coesa integradora da nação brasileira, e de um governo representante da autoridade do Estado unitário (DANTAS, 2017, p. 213).

Esses, portanto, representam os elementos estruturais clássicos do conceito tradicional de Estado enquanto ordenação social, quais sejam, povo, território e governo (DANTAS, 2017, p. 213). O interessante, nesse sentido, é a perspectiva de que esse ordenamento jurídico geral, composto pelos elementos da territorialidade, povo e politicidade (CANOTILHO, 1991, p. 14-15) acaba por representar a imposição de uma cultura dominante sobre as demais, a fim de homogeneizar a sociedade em suas crenças, ritos e padrões sociais (CUEVA, 1996, p. 49). 
O Estado moderno, calcado no racionalismo e no individualismo, surge no final do século XV em Portugal e Espanha, como ruptura do modelo medieval e sob a forma absolutista (SILVA, 2014, p. 55), haja vista a racionalidade moderna ter se cristalizado no momento em que espanhóis e portugueses se lançaram ao mar, dando origem à doutrina de exclusão e encobrimento do diverso (DUSSEL, 1994, p. 11).

Assim, a criação de uma identidade moderna foi essencial para que o Estado fosse pensado como parte da imposição da racionalidade europeia às demais sociedades, afinal, a construção da subjetividade europeia foi decorrente da negação do outro enquanto ser racional, detentor de sociabilidade e organizações próprias (SILVA, 2014, p. 42).

Foi este modelo de constitucionalismo moderno, representado pelo Estado Liberal, que é adotado pelos Estados nacionais latino-americanos, em uma clara contradição com a realidade social da América Latina, tendo em vista a pluralidade de culturas e povos indígenas que compunham a diversidade étnico-cultural da região.

Assim, o Estado nação é um ficção da cultura ocidental europeia, afinal, é impossível, na realidade da América Latina, conceber a ideia de coincidência entre Estado e nação, isso porque os povos indígenas são componentes visíveis de uma diversidade étnica, cultural e até mesmo jurídica (DANTAS, 2017, p. 221).

Ocorre que a presença dos povos indígenas como atores sociais e identidades diferenciadas sempre foi uma realidade social negada, já que o modelo de Estado-nação, considerado como culturalmente homogêneo e soberano, rechaça práticas culturais que possam representar riscos à unidade e integralidade imposta por seu projeto de identidade nacional, concebido a partir de um processo civilizatório traumático (DANTAS, 2017, p. 221).

A construção da identidade nacional se deu mediante processo civilizatório e teve como base a supressão das identidades étnicas discrepantes (RIBEIRO, 1995, p. 23), motivo pelo qual, o longo de sua história constitucional, o Brasil ficou alheio ao reconhecimento jurídico da pluralidade cultural existente em seu corpo social.

Afinal, a Constituição de 1988 consubstancia o modelo de Estado-nação vinculado ao modelo clássico, qual seja, o fundamentado pelos elementos povo, território e governo (DANTAS, 2017, p. 218). Povo esse marcado pela unicidade e coesão cultural, de forma que as populações indígenas têm destaque apenas enquanto exceções culturais ou grupos inexpressivos no contexto nacional mais amplo. 
Em outras palavras, é em decorrência do Estado ter sido formado sem a compreensão do contexto de diversidade cultural, inclusive negando-a, que a América Latina, especialmente o Brasil, enfrenta dificuldades em criar um modelo de constitucionalismo inerente à realidade latino-americana (SILVA, 2014, p. 69), obstáculo que tem sido enfrentado pelas novas Constituições da Bolívia e do Equador em um claro combate às tradições constitucionais de raízes individualistas (GARGARELLA; COURTIS, 2015, p. 21).

Assim, a importação de um modelo de Estado incompatível com a realidade plural do continente é a causa simbólica da discriminação institucional atual contra as comunidades indígenas, cujos reflexos podem ser percebidos pela prática monista de desprezo dos conhecimentos tradicionais como fontes do Direito, bem como, pela lógica, ainda vigente, de que as populações indígenas seriam adversárias da soberania nacional e do desenvolvimento econômico.

A permanência de instituições coloniais na forma de organização jurídica marca as sociedades latino-americanas, isso porque o modelo de Estado implantado baseou-se na racionalidade moderna de exclusão dos povos indígenas, negando-lhes a capacidade de autogoverno ou até mesmo os submetendo a regimes jurídicos de tutela.

Várias das instituições assentadas desde o século XVI, e principalmente no período pós-Independência, ecoam até hoje nos países da América Latina, mas uma das esferas em que a herança colonial é mais perceptível é, sem dúvida, o Direito (ACUNHA, 2019, p. 51).

Para Raquel Yrigoyen Fajardo (2011, p. 139), o Direito "é um sistema de normas, práticas, valores, procedimentos e instituições que serve para regular a vida em sociedade, resolver conflitos e organizar a ordem, possuindo legitimidade e eficácia para determinado coletivo, em certo contexto sociocultural e histórico".

Dessa forma, não se pode negar que cada comunidade indígena possui regramentos próprios de organização social e resolução de litígios, possuindo, portanto, sistemas jurídicos que lhes permitem regular a vida em sociedade de acordo com suas cosmovisões, valores e cultura. Por isso, ao negar validade a normas jurídicas produzidas no seio das comunidades tradicionais, o Estado monista rejeita parte integrante da cultura dos povos indígenas.

Segundo Guillermo O’Donnell (2006, p. 289), os sistemas jurídicos e as instituições indígenas incluem autoridades indicadas e legitimadas publicamente, procedimentos detalhados, rituais elaborados, sanções regulares e, consequentemente, têm como característica a transparência e a formalização conforme suas cosmovisões. 
Percebe-se, portanto, que os Estados nacionais relutam em reconhecer as comunidades indígenas como povos, tendo em vista que, segundo a concepção individualista e unicista do Estado moderno, um Estado possui um só povo (SOUZA FILHO, 2018, p. 84).

Ocorre que o constitucionalismo plurinacional, evidenciado pelas Constituições do Equador e da Bolívia, procura romper com a lógica da colonialidade do poder e refundar o Estado com fundamento no reconhecimento de nações indígenas (ACUNHA, 2019, p. 74), afinal, as comunidades indígenas são anteriores ao próprio corpo político estatal.

Essa perspectiva pluralista das novas experiências constitucionais latino-americanas transgride o monismo jurídico, pois acaba por oficializar o pluralismo jurídico, o que, por consequência, incorpora elementos de interculturalidade na produção do direito e reconhece mecanismos institucionais de plena eficácia para aplicação desse direito descentralizado e pluralístico (ACUNHA, 2019, p. 75).

Para Antônio Carlos Wolkmer (2015, p. 254), o pluralismo jurídico tem como característica central o reconhecimento do valor da diversidade e da diferença, cuja teoria parte da "existência de mais de uma realidade, de múltiplas formas de ação prática e da diversidade de campos sociais e culturais com particularidades próprias".

É o caso, por exemplo, dos novos princípios de organização do poder na Bolívia, que, fundamentados na interculturalidade e na igual dignidade dos povos, oportuniza a existência de uma jurisdição indígena, com competências privativas, bem como de instituições oficiais plurinacionais, como o Tribunal Constitucional Plurinacional e a Assembleia Legislativa Plurinacional (ACUNHA, 2019, p. 75).

Contudo, esse abalo na organização jurídica tradicional é identificado em apenas dois países latino-americanos, quais sejam, Bolívia e Equador, ao passo que a grande maioria dos países do continente permanece sob uma estrutura centralista do direito moderno (ACUNHA, 2019, p. 76) que despreza e rejeita tradições e formas de vida indígenas, utilizando-se de argumentos hierarquizantes de que o direito indígena seria mera tradição, em oposição a um direito ocidental moderno, positivado e cientificamente organizado.

Nesse sentido, Fernando Acunha (2019, p. 76-77) caracteriza o direito moderno como uma força centrípeta de herança colonial que relega as produções normativas alternativas às margens do sistema oficial, em oposição ao pluralismo, verdadeira força centrífuga que busca deslocar o centro decisório para as esferas fragmentárias e estabelecer uma estrutura de compartilhamento de saberes jurídicos com influências recíprocas. 
Há que se falar, portanto, em um verdadeiro declínio do projeto político-jurídico do Estado moderno, tendo em vista a evidência histórica de outras fontes e práticas jurídicas, não oficializadas pelos Estado, mas imperantes na realidade concreta de muitos povos.

O pluralismo jurídico, em sobreposição ao monismo jurídico em sede de declínio do projeto de Estado moderno, acaba por assumir o pressuposto de que existem outras fontes legítimas de produção de direito diverso do estatal, de forma a combater a hierarquização do conhecimento e possibilitar a autonomia das comunidades indígenas na tratativa de seus conflitos internos.

Assim, reconhecer as juridicidades próprias das comunidades indígenas, as quais não deixam de ser manifestações culturais, torna-se indispensável para que se estabeleça um cenário otimista de convivência harmônica que rompa com a opressão dos povos indígenas.

\section{CONSTITUCIONALISMO PLURALISTA LATINO-AMERICANO E A REFUNDAÇÃO DO ESTADO}

A crítica à herança colonial das instituições jurídicas, bem como ao modelo de Estado de Direito moderno, é apresentada pelo movimento latino-americano que instituiu ordenamentos jurídicos abertos às cosmovisões indígenas, em oposição às concepções culturalmente monolíticas e excludentes promovidas pelos Estados nacionais.

Em contramão ao discurso jurídico distante de qualquer perspectiva de interculturalidade, novos caminhos para o pensamento constitucional têm ganhado fôlego ao tentar reestruturar a relação entre Estado e povos indígenas, propondo um diálogo que permita a troca de saberes e o aprendizado recíproco em meio a uma sociedade plural.

Essa abordagem descolonial é uma das prerrogativas do movimento político e constitucional que emergiu em alguns países latino-americanos, com a proposta de um modelo alternativo de produção jurídica, o qual resgata e preserva conhecimentos e práticas históricas das comunidades indígenas.

Segundo Yrigoyen Fajardo (2011, p. 25), entre o período de 1980 a 2010, a América Latina foi palco de inovadoras reformas constitucionais em matéria indígena, responsáveis por contestar o paradigma social integracionista que, apesar de ter superado o marco do constitucionalismo liberal ao reconhecer direitos coletivos aos povos indígenas, não rompeu com a monoculturalidade nem com o monismo jurídico, inerentes ao Estado nação. 
Assim, o movimento ficou conhecimento como "horizonte do Constitucionalismo pluralista", em oposição ao constitucionalismo integracionista vigente até então, composto pelos paradigmas do constitucionalismo multicultural, do constitucionalismo pluricultural e do constitucionalismo plurinacional.

Essas reformas paradigmáticas representaram um questionamento efetivo à configuração do Estado e ao monopólio estatal na produção do Direito, tendo em vista que, até o início da década de 1980, o constitucionalismo simbolizava a consolidação do modelo monocultural e excludente de Estado comprometido com a manutenção do monismo jurídico.

O constitucionalismo multicultural é a primeira etapa do ciclo do constitucionalismo pluralista e, conforme categorização de Yrigoyen Fajardo (2011, p. 25), é representado pela Constituição do Canadá, de 1982, da Guatemala, de 1975, da Nicarágua, de 1987, e do Brasil, de 1988, pois introduzem o conceito de diversidade cultural e reconhecem direitos indígenas específicos.

Já Wolkmer (2013, p. 30), inspirado pela classificação da autora, defende que os grandes marcos da primeira etapa do constitucionalismo multicultural são a Constituição brasileira de 1988 e a colombiana de 1991, aquela porque consolidou perspectivas pluriétnicas e multiculturais, e essa pois inaugurou importantes garantias jurisdicionais de proteção dos povos indígenas.

Para o autor, a Constituição colombiana de 1991 foi responsável por ampliar o rol de direitos e inaugurar uma jurisdição especial para o exercício jurisdicional das autoridades indígenas em âmbito de seu território, contribuindo para o desenvolvimento do pluralismo jurídico ao reconhecer outras formas de organização social para além da estatal (WOLKMER, 2013, p. 31).

Apesar da pontual distinção de classificação, tendo em vista que Wolkmer insere a Constituição colombiana na primeira etapa do ciclo multicultural, enquanto Fajardo a inclui no ciclo pluricultural, ambos os autores reconhecem a importância do precedente para a incorporação das cosmovisões indígenas no campo constitucional.

Assim, o advento do multiculturalismo na região se deu como uma conquista paradigmática de sobreposição jurídico-institucional da antiga concepção integracionista. Sem, contudo, modificar o caráter no Estado, nem legitimar as instituições políticas e jurídicas próprias das comunidades indígenas, tendo em vista que este momento 
constitucional foi marcado pela influência da Convenção 107 da OIT e seu viés ainda integracionista.

A despeito de não reconhecer de forma explícita o pluralismo jurídico, o ciclo multicultural foi o responsável por primeiro reconhecer a diversidade cultural e linguística das sociedades latino-americanas, bem como, assegurar os direitos dos povos indígenas a um território próprio (ACUNHA, 2019, p. 70), representando um passo histórico rumo à crítica ao Estado nação e à superação do monismo jurídico que se dará adiante.

Em seguida, o constitucionalismo pluricultural, ciclo constitucional marcado pela influência da Convenção 169 da OIT, aprimora as conquistas do multiculturalismo ao desenvolver a perspectiva de Estado pluricultural e ao ampliar a participação institucional dos povos indígenas, assegurando meios concretos para sua autonomia.

Esta segunda etapa caracteriza-se pela perspectiva do pluriculturalismo que, segundo Yrigoyen Fajardo (2011, p. 142), estabelece formas de pluralismo jurídico que objetivam romper com o monismo jurídico do modelo de Estado nação vigente, consagrando, entre outros, direitos como a oficialização de idiomas indígenas, o acesso à educação bilíngue e pluricultural e novas formas de participação e consulta dos povos indígenas.

Ainda segundo a autora, as experiências constitucionais que integram o ciclo do constitucionalismo pluricultural são as Constituições da Colômbia, de 1991, do Paraguai, de 1992, do Peru, de 1993, da Bolívia, de 1994, da Argentina, de 1994, e da Venezuela, de 1999 (YRIGOYEN FAJARDO, 2011, p. 25).

Apesar desse segundo ciclo do constitucionalismo pluralista ser marcado por concessões de exercício de poder às autoridades indígenas, o pluriculturalismo não possibilitou o abandono da tutela estatal, pois estão presentes limitações à autonomia indígena, o que impede uma real abertura ao pluralismo jurídico orgânico e sistemático e restringe a eficácia da outorga constitucional de direitos (ACUNHA, 2019, p. 72).

Inclusive, Pedro Brandão (2015, p. 32) defende que o constitucionalismo pluricultural acabou por criar uma espécie de pluralismo jurídico subordinado e colonial, pois as Constituições representantes desse ciclo estabeleceram cláusulas de freio incorporadas aos textos constitucionais como restrições à autonomia indígena.

É o caso da atuação da Corte Constitucional colombiana na deliberação de conflitos entre a jurisdição comum ordinária e a especial indígena, pois é necessário que a Corte interprete interculturalmente os princípios constitucionais conforme as circunstâncias do caso 
concreto, nada obstando que uma virada jurisprudencial passe a obstaculizar a efetivação da autonomia indígena, sob o pretexto abstrato de defesa da Constituição (BRANDÃO, 2015, p. 104).

Outro exemplo da atuação limitadora à autonomia indígena, ainda, é o art. 260 da Constituição venezuelana de 1999, que viabiliza a aplicação do sistema de Justiça indígena, fundamentado nas crenças e tradições indígenas, desde que estes estejam de acordo com o marco constitucional, com a lei e com a ordem pública.

Logo, inegáveis são os avanços promovidos pelo ciclo pluricultural, no entanto, a ausência de mecanismos orgânicos institucionais que acompanhem a constitucionalização de direitos acaba por limitar a eficácia dessas reformas constitucionais, impedindo que essas conquistas sejam traduzidas em avanços reais para as comunidades indígenas.

Por fim, o terceiro ciclo traz o paradigma da plurinacionalidade e propõe a refundação do Estado a partir do reconhecimento de nações indígenas preexistentes ao corpo político estatal, além de ampliar a positivação de direitos de matriz indígena, como o bem viver, o direito à água e a Pachamama (ACUNHA, 2019, p. 74).

É com o constitucionalismo plurinacional que adveio uma verdadeira ruptura com a lógica constitucional monista, pois, a partir das Constituições do Equador, de 2008, e da Bolívia, de 2009, as cosmovisões indígenas foram internalizadas e consagradas como normas constitucionais próprias, mas também, além dos elementos de interculturalidade na produção do direito, foi oficializado o pluralismo jurídico, mediante mecanismos institucionais de jurisdição indígena para aplicação de um direito efetivamente plural.

Essas Constituições têm claro viés descolonizador e intercultural, visto que estabelecem novos princípios de organização do poder que permitem a afirmação de uma jurisdição autônoma indígena igualitária à ordinária, além de instaurar instituições oficiais notoriamente plurinacionais, como é o caso do Tribunal Constitucional Plurinacional boliviano (BRANDÃO, 2015, p. 33).

No caso da Bolívia, as disposições normativas que incorporam a plurinacionalidade vão além do preâmbulo e dos artigos inaugurais, pois materializam-se ao longo de todo o texto constitucional, seja pelas disposições que asseguram a autonomia das nações e povos indígenas, na forma dos artigos 289 a 296, ou das que oficializam o pluralismo jurídico ao conferir valor normativo às decisões da jurisdição indígena, conforme artigos 190 a 192, ou, 
ainda, pelas disposições que regulam a representação proporcional plurinacional dos Poderes, na forma dos artigos 147, inciso II, 187 e 197, inciso I.

Já a Constituição equatoriana, além de afirmar a natureza plurinacional do Estado, propõe expressamente a coexistência harmônica entre as nacionalidades indígenas, na forma de seu artigo $6^{\circ}$, bem como reconhece o pluralismo jurídico ao garantir a autonomia da jurisdição indígena, conforme artigo 171.

O rompimento com a teoria constitucional tradicional, bem como com a racionalidade monolítica inerente ao Direito moderno, pode ser vislumbrado pela incorporação da concepção de viver bem, denominado suma qamaña na língua aymara, prevista no artigo $8^{\circ}$ da Constituição boliviana, ou sumak kawsay na língua kichwa, previsto no artigo 14 da Constituição equatoriana, como tentativa de harmonização entre postulados tradicionais e disposições normativas inspiradas nos conhecimentos ancestrais e cosmovisões indígenas (ACUNHA, 2019, p. 149).

$\mathrm{Na}$ construção contra hegemônica de uma sociedade de novas perspectivas epistemológicas, novos direitos fundamentais são concebidos com o objetivo de melhor articular a relação entre o ser humano e a biosfera, é o caso da positivação dos direitos à água, à soberania alimentar e ao bem viver, de modo a entrelaçar conhecimentos indígenas ancestrais com o saber ocidental moderno (BRANDÃO, 2015, p. 154).

Para Acunha (2019, p. 150), a simbiose de elementos provenientes de tradições jurídicas tão distintas promove um novo modelo de desenvolvimento econômico, seja a partir da substituição da acumulação individual pelo equilíbrio com o meio ambiente, seja pelo diálogo intercultural entre campos de conhecimentos para aprendizagem recíproca.

O princípio do bem viver, portanto, rege as Constituições do ciclo constitucionalista plurinacional, representando a resistência dos povos indígenas contra o poder econômico, e consolida um modo alternativo de produção que rechaça a lógica colonial de exploração da natureza, de modo a contestar o modelo neoliberal de postulados materialistas e resgatar a cosmovisão ancestral de ligação entre o indivíduo e a Mãe Terra (BRANDÃO, 2015, p. 163).

Dessa forma, as Constituições do Equador e da Bolívia destacam-se não apenas pela introdução de novos direitos e garantias constitucionais, mas sim pelo pensamento póscolonial que baseia uma nova lógica de organização social, refundando o Estado a partir da proposta de um Estado plurinacional que se contrapõe à uniformização cultural, política e jurídica concebida pela modernidade europeia ocidental. 
Portanto, o constitucionalismo latino-americano que formula um novo paradigma constitucional é pautado pela plurinacionalidade, isto é, pela proposta não hegemônica de existência de uma cultura compartilhada entre várias nações dentro de uma sociedade, em detrimento de uma matriz estatal excludente que não reconhece percepções de mundo construídas fora do centro gravitacional da racionalidade moderna.

Esse pluralismo de perspectivas dá voz aos setores historicamente excluídos e transforma a engenharia constitucional dos países com passado colonial, criando instituições interculturais dispostas a promover o diálogo com a diversidade e pluralidade existentes no contexto latino-americano.

\section{DESAFIOS DA DESOBEDIÊNCIA EPISTEMOLÓGICA}

O constitucionalismo plurinacional trouxe consigo o peso da demanda por uma libertação da América Latina em relação à incessante opressão e desigualdade presentes na região, de forma que se criou a expectativa de concepção de uma realidade institucional que confronte os profundos legados do colonialismo.

A crença em uma normatividade transformadora, proposta pelo pioneirismo do projeto intercultural do Estado, subestima a fragilidade do direito como instrumento desafiador do sistema internacional, capaz de se apoiar nas assimetrias produzidas pelo colonialismo. Por mais impulsionadores que sejam os desenhos institucionais construídos, não há como negar o papel dos agentes políticos e econômicos globais sobre a realidade dos países periféricos.

Por isso, em primeiro lugar, imperioso o reconhecimento dos impactos da colonialidade na cultura política-jurídica da América-Latina, que, segundo a tese de Aníbal Quijano (2005), pode exprimir-se nas formas da colonialidade do poder, do saber e do ser.

Nesse sentido, o conceito de colonialidade não retrata apenas a imposição política e econômica exercida pelos Estados sobre minorias étnicas, mas também remete a um fenômeno complexo de subordinação epistemológica. A adoção do clássico modelo de Estado nação, por exemplo, representa uma faceta da colonialidade do poder, pois submete os povos indígenas a uma unidade política pensada para garantir a concentração do poder na região (LACERDA, 2014, p. 35).

Outro ponto importante da discussão de ordem epistemológica é a visão eurocêntrica de conhecimento construída pela colonialidade do saber, a qual estabelece, segundo Lacerda 
(2014, p. 37) "uma escala hierárquica em que o grau de validade do conhecimento tende a decair à medida que seu núcleo de produção se afasta do centro gravitacional estabelecido pela ordem colonial".

Sendo assim, torna-se necessária uma emancipação social construída a partir do Sul simbólico dos oprimidos, conforme bem aponta Boaventura de Sousa Santos (2009, p. 26) ao conceber a ideia de epistemologias do Sul, a qual se caracteriza pela existência de um pensamento considerado abissal que estabelece uma hierarquia entre pensamentos, enquanto uns são considerados relevantes, outros são considerados incompreensíveis e afastados da racionalidade.

Ou seja, no plano epistemológico, o pensamento moderno tem caráter abissal, já que inferioriza outros campos do conhecimento, como as cosmovisões indígenas, de forma que o único conhecimento válido seria aquele produzido pela monocultura eurocêntrica.

Logo, a ideia de inexistência de conhecimentos jurídico-políticos produzidos pelas comunidades indígenas, sujeitos coletivos considerados incapazes de contribuírem para a construção de um Estado, retrata um pensamento abissal que inferioriza as formas de saber próprias dos povos colonizados (LACERDA, 2014, p. 38).

A terceira dimensão da colonialidade acaba por resultar do exercício das anteriores, tendo em vista que a negativa, por parte do Estado nação, em reconhecer as coletividades indígenas como verdadeiras nações e povos, é uma faceta da colonialidade do ser, pois repercute em sua identidade e subjetividade.

Diante desse complexo processo, alguns autores entendem a colonialidade como a paradoxal energia que gera a descolonialidade (MIGNOLO, 2010, p. 126), um contra movimento que, na América Latina, foi responsável pela construção de modelos plurinacionais de Estado.

Dessa forma, o Estado plurinacional representa um desdobramento do que se considera uma desobediência epistêmica (LACERDA, 2014, p. 34), pois foi construído a partir do rompimento com a concepção clássica de identidade nacional e de hegemonia cultural.

Para Mignolo (2010, p. 323), no intuito de se desprender da relação de colonialidade e romper com a lógica eurocêntrica de produção de conhecimento, é necessária uma postura de desobediência epistêmica que promova a compreensão do mundo através das lógicas e formas político-jurídicas não hegemônicas, advindas das próprias comunidades indígenas. 
Por esse motivo, não há que se falar em multiculturalismo, mas sim em interculturalidade crítica, tendo em vista que não basta o mero reconhecimento de múltiplas culturas, devendo haver crítica ao legado eurocêntrico das instituições estatais e ao monopólio de produção jurídica, já que a inclusão das comunidades indígenas em um modelo de Estado monocultural reprodutor da colonialidade do poder, não transforma a realidade concreta.

Enquanto o multiculturalismo pressupõe a existência de uma cultura dominante que tolera a existência de outras culturas dentro do espaço cultural que domina, a interculturalidade destaca-se pelo reconhecimento recíproco de várias culturas que partilham o mesmo espaço cultural para enriquecimento mútuo (SANTOS, 2010, p. 9).

As raízes coloniais das estruturas político-jurídicas vigentes na atualidade são contestadas a partir da construção de um modelo estatal comprometido com o diálogo intercultural, o qual pressupõe uma abertura da produção jurídica às cosmovisões indígenas, bem como, à aplicação e interpretação das normas de maneira a considerar percepções plurais de realidade.

Assim, verifica-se a importância da criação de padrões jurídicos de normatividade descolonial, capazes de influir na integração de lutas pela denúncia de arranjos institucionais excludentes e violações de direitos, em âmbito transnacional e internacional, tendo em vista que o combate às relações coloniais historicamente construídas tem fundamento em princípios como a interculturalidade e desobediência epistêmica.

A descolonização político-jurídica, portanto, torna-se um imperativo de combate ao Estado monocultural e eurocêntrico, retratando a síntese da resistência e mobilização dos povos indígenas contra a imposição cultural e epistemológica que marcou o histórico de formação do Estado, sendo que esses atos de insurgência indígena contribuem para o processo de aproximação jurídica e social em escala global.

Cabe destacar, contudo, o questionamento trazido por diferentes autores quanto às contradições existentes entre o ambiente, regional e internacional, e as evoluções normativoconstitucionais latino-americanas. Nesse sentido, Acunha (2019, p. 242) demonstra a relação conflituosa entre o funcionamento das instituições políticas e as inovações propostas pelo constitucionalismo plurinacional, da qual decorre poucos resultados genuinamente transgressores.

A estruturação do ideal da plurinacionalidade vai além da simples enunciação constitucional, pois depende da efetiva alteração da distribuição do poder político e 
econômico que, muitas vezes, sujeita-se às relações construídas em escala global, motivo pelo qual os avanços impactaram muito mais no campo normativo do que no combate à concentração de poderes.

Não há dúvidas de que a abertura do texto constitucional às cosmovisões indígenas, partindo do reconhecimento de formas alternativas de vida historicamente suprimidas, cumpre o papel simbólico de trazer para o centro do debate constitucional temas nunca antes contemplados pelo paradigma antropocêntrico ocidental. No entanto, parece inegável que a capacidade normativa de países da periferia global é prejudicada pela prática de relações assimétricas de poder em âmbito internacional, que resulta em uma opressão da racionalidade jurídica (NEVES, 2013, p. 98).

Portanto, embora dispostas a normatizar formas de produção político-jurídicas alternativas ao pensamento tradicional, as Constituições do Equador e da Bolívia envolvem-se por um cenário político, jurídico e econômico internacional completamente hostil ao seu projeto descolonial (ACUNHA, 2019, p. 236).

É o que se depreende pela análise de posturas políticas de nítido cunho econômico adotadas pelo governo boliviano e equatoriano, a despeito do que está previsto em suas Constituições. É o caso da edição do Decreto Supremo n ${ }^{\circ} 2366$ que retirou a proteção ambiental do Território Indígena e Parque Nacional Isiboro Sécure na Bolívia, permitindo a construção de uma estrada na região ${ }^{3}$, e da aprovação do projeto de exploração de petróleo no parque nacional Yasuní, localizado na Amazônia equatoriana 4 .

Logo, a positivação da cosmologia indígena do bem viver, nas Constituições do ciclo plurinacional, demonstra-se incompatível com o próprio caráter dependente da economia desses países, onde se perpetua modelos extrativistas na tentativa de satisfazer interesses econômicos a despeito do paradigma ecocêntrico implementado em nível constitucional (ACUNHA, 2019, p. 243).

\footnotetext{
${ }^{3}$ Decreto Supremo No 2366 Evo Morales Ayma Presidente Constitucional del Estado Plurinacional de Bolivia. Archivo Documental Isiboro Sécure, 2018. Disponível em: https://tipnisbolivia.org/2018/11/19/decreto-supremo-n-2366-evo-morales-ayma-presidenteconstitucional-del-estado-plurinacional-de-bolivial. Acesso em: 01/05/2020.

${ }^{4}$ Equador já produz petróleo no campo de Tiputini, próximo ao parque nacional Yasuní. Instituto Humanitas Unisinos, 2016. Disponível em: http://www.ihu.unisinos.br/185-noticias/noticias2016/560857-equador-ja-produz-petroleo-no-campo-de-tiputini-proximo-ao-parque-nacional-yasuni.
}

Acesso em: 01/05/2020. 
Apesar da aposta na construção de um modelo plurinacional de Estado ter representado ruptura em menor grau do que a esperada, o rompimento com a matriz colonial demanda um longo processo de descoberta de soluções. É o que afirma Boaventura de Sousa Santos (2015, p. 210) ao defender o experimentalismo como principal característica do processo de superação do Estado monista, pois "a ruptura mais fundamental com o constitucionalismo moderno eurocêntrico é a instituição de um Estado experimental".

Portanto, o constitucionalismo plurinacional apostou na normatividade como instrumento capaz de transformar a realidade de grupos historicamente oprimidos, sem, contudo, contar com o confronto de um sistema internacional avesso à pluralidade que contesta o fetichismo econômico imperante na escala global.

Assim, o ainda presente antagonismo entre o texto constitucional e a realidade concreta não é suficiente para desacreditar a experiência jurídica e a nova institucionalidade dos projetos plurinacionais, apenas se pontua que a plena potencialidade dos projetos depende da consciência dos limites políticos, econômicos e internacionais vigentes na região.

\section{CONSIDERAÇÕES FINAIS}

Ante a incursão teórica percorrida, observou-se que as juridicidades dos povos indígenas vinculam-se às organizações sociais e à concretude de uma vida cultural que contrariam o individualismo e a racionalidade moderna, elementos basilares do Estado moderno e do monismo jurídico.

A despeito da realidade plural e da evidente diversidade étnico-cultural intrínsecas à região, os fundamentos substanciais do sistema jurídico instaurado na América Latina permanecem os mesmos desde a colonização, cuja composição arraigou-se na concepção de Estado nação e na exclusão das comunidades indígenas da ordem política moderna.

Em contrapartida, a relativização dos Estados nacionais e o reconhecimento de autonomias culturais aos povos indígenas configuram-se como uma realidade na contemporaneidade. Graças à nova leitura do direito constitucional, proporcionada pelo arranjo institucional dos Estados Plurinacionais, foi possível provocar rachaduras no 
absolutismo jurídico e no formalismo estatal por meio da oficialização do pluralismo jurídico intercultural e da superação do conceito de identidade nacional homogênea.

Restou-se claro que os ciclos de reformas constitucionais que se deram na América Latina, além de questionar os enunciados do constitucionalismo eurocêntrico, é um movimento que busca propor um novo modelo de sociedade ao redesenhar a engenharia institucional dos países foco das diversas facetas do colonialismo, fazendo-se emergir perspectivas ignoradas e atores sociais silenciados ao longo da história jurídica do continente.

Não há como negar, no entanto, a incompletude dos projetos descoloniais frente à lógica internacional reprodutora das assimetrias criadas pelo colonialismo, tendo em vista que muitos dos países do Sul global ainda perpetuam modelos econômicos extrativistas, a despeito, como é o caso da Bolívia e do Equador, dos mandamentos constitucionais de sustentabilidade ambiental, do bem viver, e da preservação das formas de vida das comunidades tradicionais.

Logo, vislumbra-se a necessidade de um pensamento jurídico crítico ao processo de colonização da teoria constitucional, disposto a reafirmar a posição de países latinoamericanos na reflexão sobre fenômenos jurídicos sem apostar em um normatividade transformadora como única escapatória das estruturas coloniais de dominação.

É, portanto, diante desse incerto cenário que se constata a relevância do debate constitucional a respeito das contribuições do constitucionalismo latino-americano para a ordem jurídica brasileira, sem que, contudo, se perca de vista que o longo processo de descoberta de soluções contra as facetas da colonialidade vai além das mudanças de cunho estritamente normativo.

Ao reconhecer as limitações do sistema jurídico regional e a fragilidade do direito como instrumento transformador da realidade social, compreende-se que respostas unilaterais demonstraram-se ineficazes, pois estabelecidas sem considerar as relações assimétricas mantidas em escala global, motivo pelo qual a América Latina encontra-se, ainda, no intermédio do progresso rumo à interculturalidade.

\section{REFERÊNCIAS BIBLIOGRÁFICAS}

ACUNHA, Fernando José Gonçalves. Constitucionalismo, Autoritarismo e Democracia na América Latina. Belo Horizonte: Fórum, 2019.

BRANDÃO, Pedro. O Novo Constitucionalismo Pluralista Latino-Americano. Rio de 
Janeiro: Lumen Juris, 2015.

CANOTILHO. José J. Gomes. Direito Constitucional. 5. ed. Coimbra: Almedina, 1991.

CUEVA, Mario de La. La Idea Del Estado. Cidade do México: Fondo de Cultura Económica, 1996.

DANTAS, Fernando Antônio de Carvalho. Entre a nação imaginada e o estado plurinacional: o reconhecimento dos direitos indígenas no novo constitucionalismo latino-americano. In: AVRITZER, Leonardo; GOMES, Lilian Cristina Bernardo (Org.). O constitucionalismo democrático latino-americano em debate. Belo Horizonte: Autêntica, 2017, p. 213-230.

DUSSEL, Enrique. El encubrimiento Del Otro: hacia El origen del mito de la Modernidad. La Paz: Plural, 1994.

GARGARELLA, Roberto; COURTIS, Christian. El Nuevo Constitucionalismo Latinoamericano: Promesas e Interrogantes. In: BALDI, César Augusto (coord). Aprender desde o Sul: Novas Constitucionalidades, Pluralismo Jurídico e Plurinacionalidade Aprendendo desde o Sul. Belo Horizonte: Fórum, 2015, p. 59-85.

LACERDA, Rosane Freire. "Volveré, y Seré Millones": contribuições descoloniais do movimentos indígenas latino americanos para a superação do mito do Estado-Nação. Tese de doutorado. Faculdade de Direito, UnB, 2014.

MIGNOLO, Walter. Desobediencia epistémica: retórica de la modernidad, lógica de la colonialidad y gramática de la descolonialidad. Buenos Aires: Del Signo, 2010.

NEVES, Marcelo. Del pluralismo jurídico a la miscelánea social: el problema de la falta de identidad de la(s) esfera(s) de juridicidad en la modernidad periférica y sus implicaciones en América Latina. In: GARCÍA VILLEGAS, Mauricio; RODRÍGUEZ, César A. (eds.). Derecho y Sociedad en América Latina: un debate sobre los estudios jurídicos críticos. Bogotá: ILSA, 2003, p. 261-290. Colección En Clave de Sur.

O'DONNELL, Guillermo. Afterword: On Informal Institutions, Once Again. ${ }^{\circ}$ In: HELMKE, Gretchen; LEVITSKY, Steven (ed.). Informal Institutions \& Democracy: Lessons from Latin America. Baltimore, EUA: Johns Hopkins University Press, 2006, p. 285-289.

QUIJANO, Aníbal. Colonialidade do Poder, Eurocentrismo e América Latina. In: Edgardo LANDER (Org.). A Colonialidade do saber: Eurocentrismo e ciências sociais. Perspectivas latinoamericanas. Colección Sur Sur, CLACSO, Ciudad Autônoma de Buenos Aires, 2005.

RIBEIRO, Darcy. O povo brasileiro: a formação e o sentido do Brasil. São Paulo: Companhia das Letras, 1995.

SANTOS, Boaventura de Sousa. Para além do Pensamento Abissal: das Linhas Globais a uma Ecologia de Saberes. In: Boaventura de SOUSA SANTOS e Maria Paula MENESES (Orgs.) Epistemologias do Sul. Coimbra: Almedina, 2009.

; MENESES, Maria Paula Introdução. In: SANTOS, Boaventura de Sousa; MENESES, Maria Paula(Orgs.) Epistemologias do Sul. São Paulo: Editora Cortez, 2010.

La Refundación del Estado y los Falsos Positivos. In: BALDI, César Augusto

Revista de Movimentos Sociais e Conflitos | e-ISSN: 2525-9830 | Evento Virtual | v. 6 | n. 1 |

p. 15-34 | Jan/Jun. 2020 
(Coord.). Aprender desde o Sul: Novas Constitucionalidades, Pluralismo Jurídico e Plurinacionalidade. Belo Horizonte: Fórum, 2015, p. 179-214.

SILVA, Heleno Florindo da. Teoria do estado plurinacional: novo constitucionalismo latino-americano e os direitos humanos. Curitiba: Juruá, 2014.

SOUZA FILHO, Carlos Frederico Marés. Marco temporal e direitos coletivos. In: CUNHA, Manuela Carneiro da; BARBOSA, Samuel Rodrigues (Orgs.). Direitos dos povos indígenas em disputa. São Paulo: Editora Unesp, 2018, p. 75-100.

WOLKMER, Antonio Carlos. Pluralismo crítico e perspectivas para um constitucionalismo na América Latina. In: WOLKMER, Antonio Carlos; MELO Milena Petters (Orgs.). Constitucionalismo latino-americano: tendências contemporâneas. Curitiba: Juruá, 2013, p. $19-42$.

. Constitucionalismo e Pluralismo na Trajetória do Direito Brasileiro. In: BALDI, César Augusto (coord). Aprender desde o Sul: Novas Constitucionalidades, Pluralismo Jurídico e Plurinacionalidade Aprendendo desde o Sul. Belo Horizonte: Fórum, 2015, p. 253262.

YRIGOYEN FAJARDO, Raquel Z. El horizonte del constitucionalismo pluralista: del multiculturalismo a la descolonización. ${ }^{\circ}$ In: GARAVITO, César Rodríguez (coord.). El derecho en América Latina: Un mapa para el pensamiento jurídico del siglo XXI. Buenos Aires: Siglo Veintiuno, 2011, p. 139-160. 